\title{
How to handle oligometastatic disease in nonsmall cell lung cancer
}

\author{
Florian Eichhorn ${ }^{1,2}$ and Hauke Winter ${ }^{1,2}$ \\ Number 1 in the Series "Thoracic oncology" \\ Edited by Rudolf Huber and Peter Dorfmüller
}

\begin{abstract}
Affiliations: 'Dept of Thoracic Surgery, Thoraxklinik, University Hospital Heidelberg, Heidelberg, Germany. ${ }^{2}$ Translational Lung Research Center (TLRC), Member of the German Center for Lung Research (DZL), Heidelberg, Germany.
\end{abstract}

Correspondence: Hauke Winter, Dept of Thoracic Surgery, Thoraxklinik, Heidelberg University Hospital, Roentgenstraße 1, 69126 Heidelberg, Germany. E-mail: hauke.winterlamed.uni-heidelberg.de

@ERSpublications

Lung cancer patients with oligometastatic disease can profit from local ablative therapy of primary and all extrathoracic lesions. Treatment should follow a multidisciplinary decision and be restricted to limited brain, lung and adrenal metastases. https://bit.ly/3drd619

Cite this article as: Eichhorn F, Winter H. How to handle oligometastatic disease in nonsmall cell lung cancer. Eur Respir Rev 2021; 30: 200234 [https://doi.org/10.1183/16000617.0234-2020].

ABSTRACT Patients with nonsmall cell lung cancer and limited metastatic disease have been defined as oligometastatic if local ablative therapy of all lesions is amenable. Evidence from different clinical retrospective series suggests that this subgroup harbours better prognosis than other stage IV patients. However, most reports have included patients with inconsistent numbers of metastases in different locations treated by a variety of invasive and noninvasive therapies. As long as further results from randomised clinical trials are awaited, treatment decision follows an interdisciplinary debate in each individual case. Surgery and radiotherapy should capture a dominant role in the treatment course offering the option of a curative-intended local therapy in combination with a systemic therapy based on an interdisciplinary decision. This review summarises the current treatment standard in oligometastatic lung cancer with focus on an ablative therapy for both lung primary and distant metastases in prognostically favourable locations.

\section{Introduction}

Lung cancer is one of the leading causes of death worldwide $[1,2]$. Nonsmall cell lung cancer (NSCLC) histology is found in up to $80 \%$ of patients, and two-thirds present with metastatic disease at first diagnosis [3, 4]. For lack of curative treatment options, overall survival of metastasised patients is devastating and estimated to be only $4-6 \%$ at 5 years $[5,6]$. However, a subset of patients initially presents with synchronous solitary metastatic disease at the time of the diagnosis. This was taken into consideration in the 8th edition of the tumour, node, metastasis (TNM) staging system defining distinct prognostic descriptors for metastatic disease: M1a (lung metastases), M1b (solitary extrathoracic metastasis) and M1c (multiple extrathoracic metastases) [7], the latter associated with the worst prognosis. For localised intraand extrathoracic metastases, local ablative therapy with curative intent of all tumour sites may be discussed as a separate treatment option [8-10]. Treatment concepts for these patients are included in the current guidelines [11-13]. In recent years it has been shown in a number of retrospective trials that these patients may benefit from an aggressive ablative therapy of both the primary lung tumour and the distant

Provenance: Commissioned article, peer reviewed.

Received: 20 July 2020 | Accepted after revision: 7 Oct 2020

Copyright CERS 2021. This article is open access and distributed under the terms of the Creative Commons Attribution Non-Commercial Licence 4.0. 
organ metastases $[14,15]$. The most data exist for the treatment of localised (contralateral) lung, brain and adrenal metastases $[16,17]$. However, the definition of oligometastatic state is not consistent and patients with different local treatment regiments and up to five isolated metastases have been included in trials.

This review summarises current treatment strategies for lung cancer patients diagnosed with "oligometastatic lung cancer" with focus on surgery and local ablative radiotherapy.

\section{Definition of the oligmetastatic situation and prognostic implications}

The term "oligometastases" was proposed by Hellman and Weichselbaum [18] in an editorial in 1995. Following the "seed and soil" hypothesis by PAGET [19] in 1889 it takes the biology of the primary tumour and the receptivity of the host's organs into account. Oligometastatic disease can be described as a comparatively early metastasised tumour stage with a limited number of separate distinct organ metastases, as opposed to a diffuse metastasised disease. Due to their limited tumour burden, these patients may profit from a radical ablative therapy of both the primary lesion and all metastatic sites [16, 20-22]. A standardised definition of oligometastatic disease in terms of location and number of metastases has not yet been established. Nevertheless, up to five lesions in up to three different organs are generally considered as oligometastatic.

The 8th edition of the TNM staging system defines M1b as a single metastatic lesion in a single extrathoracic location. Two or more metastases are classified as M1c, but can still be addressed as oligometastatic.

An important prognostic factor is the chronological appearance of the metastases. Patients with metachronous metastases diagnosed after the primary lung cancer have a better prognosis than patients with synchronously detected distant lesions. In this context, NiIBE and HaYAKAWA [23] proposed exclusive use of the term "oligometastases" only in a situation with simultaneous occurrence of the primary tumour and distant metastases. In contrast, a new metastatic site in a controlled or curatively treated primary tumour lesion should rather be defined as "oligorecurrence" of the disease.

A meta-analysis of 757 NSCLC patients with oligometastases was performed by AsHwORTH et al. [24] in order to identify a clinical strategy in this specific situation. They retrospectively reviewed data of 20 centres worldwide. Only patients with controlled primary lung cancer who had undergone surgery and radiotherapy were included. They could show that $47.8 \%$ of the patients with metachronous metastases had an overall survival of 5 years. In contrast, patients with synchronously metastasised lung cancer and patients with no evidence of lymph node metastases had an overall survival of $36.2 \%$. Patients with a synchronous metastatic disease and mediastinal and/or hilar lymph node metastases had an overall survival of $13.8 \%$. Based on these findings, Ashworth et al. [24] defined three patient groups with a distinct risk profile for survival: 1) low-risk group including patients with metachronous metastases; 2) intermediate-risk group with metachronous metastases and no evidence of nodal disease; and 3) a high-risk group (synchronous and N1/N2 disease).

\section{Ablative techniques in the treatment of oligometastases}

Surgical metastasectomy has been the ablative technique most often applied to treat oligometastatic disease. Resection of solitary brain metastases in NSCLC patients has been reported for 50 years [25-27]. Metastases of the lung or adrenal glands were also resected in clinical practice in patients with no further evidence of tumour burden. Nevertheless, few data exist solely examining the surgical approach for both primary and metastatic site. A retrospective series of 99 patients with surgical therapy in synchronous solitary metastases reported an overall 5-year survival of 38\% [28]. Comparable survival of $36 \%$ at 5 years was found by Collaud et al. [29] investigating survival of 29 surgically treated patients with single-organ metastases.

Stereotactic body radiation therapy (SBRT) or stereotactic ablative radiotherapy offer a high conformal ablative radiotherapy of short duration and minimal damage of the surrounding noncancerous tissue [30]. Initially, SBRT was mainly used as radiosurgical treatment for brain metastases. The local control achieved is comparable to studies analysing conventional surgical resection of brain metastases [31]. The rapid development in high-dose ablative radiation techniques, as well as the broad availability of SBRT resulted in its regular utilisation for the treatment of extracranial oligometastatic disease [32, 33].

Radiofrequency ablation is a therapeutic option for the treatment of patients with early-stage lung cancer who are functionally inoperable or of patients with localised recurrent primary lung cancer [34, 35]. Furthermore, it was applied to patients with lung metastases of solid tumours of different origin [36]. Nevertheless, its role in the treatment for distant lesions in oligometastatic NSCLC has not been comprehensively investigated, but its therapeutic potential was shown in smaller retrospective cohorts of patients $[37,38]$. Nevertheless, the possibility of a repetitive radiofrequency ablation at the same location, 
and the option of a histological examination can be stated as the main advantage of this technique over SBRT.

\section{Lung oligometastases}

Approximately one-fifth of the patients with NSCLC disease develop localised pulmonary metastases [8, 17]. Following the TNM staging system, contralateral lung metastases in oligometastatic NSCLC are clinically classified as M1a. Ipsilateral separate tumour nodules are classified as T3 for metastases in the same lobe and T4 for metastases in a separate ipsilateral lobe, due to their better prognosis [39, 40]. Separately located lung lesions afford special interest in an oligometastatic disease as it is often technically demanding to differentiate between a lung metastasis originating from the primary NSCLC and a secondary lung cancer. Depending on the clinical interpretation at staging, prognostic discussion ranges from comparably favourable (two separate early cancers: stages I-II) to very poor (metastasis: stage IV). In 1975, MARTINI and Melamed [41] proposed to solve the diagnostic dilemma by taking into account the location and the interval between diagnosis and histology. They assumed that a metachronously occurring pulmonary nodule in a separate lobe is more likely to be a secondary primary lung cancer. A simultaneously occurring ipsilateral lesion is more likely to be a pulmonary metastasis. Nevertheless, even in case of an identical histology a metastasis cannot be distinguished without doubt from a secondary lung cancer. Molecular characterisation of 42 distinct NSCLCs contradicted the Martini-Melamed criteria in 32\% of the patients, as reported by GIRARD et al. [42]. LIU et al. [43] performed genomic analyses of 15 pulmonary presumably metastatic lesions showing that a secondary separate lung cancer was apparent in all patients. In contrast, synchronous metastases were confirmed in $62 \%$ of the patients with multifocal adeno- and squamous cell carcinoma by clonality analysis in a series of 78 patients examined by WARTH et al. [44].

The reported uncertainty and the technically demanding complexity of these analyses support a local ablative treatment for both putative primary lung cancer and pulmonary (oligo-) metastases in a curative intent as far as functionally achievable.

Most retrospective series investigating surgery for lung metastases contain bilateral resections, and histological data are not always available. Analysis of the "oligo"-subgroups (same histology, contralateral lung metastasis) shows 5-year survival rates of $49 \%$ in a series by FABIAN et al. [45]. DE LEYN et al. [46] performed bilateral resections in 36 patients for synchronous pulmonary lesions, $50 \%$ of them were of the same histology. Survival of these patients was $31 \%$ at 5 years. There was no survival difference observed between limited or anatomical extent of resection. Comparable survival data (34\%) were reported by Voltolini et al. [47] analysing 28 patients. Even though systematic nodal dissection was not routinely performed, involvement of mediastinal or hilar lymph node metastases was associated with a worse prognosis. Perioperative mortality following pulmonary metastasectomy (cancers of different origin) was reported at $1 \%$ in a large series [22]. It can be assumed that resection of pulmonary metastases originating from NSCLC is associated with comparably low perioperative mortality rates in physically fit patients. $\mathrm{HE}$ et al. [48] investigated 21 patients with surgically treated NSCLC with one to five additional pulmonary metastases. A pulmonary metastasectomy was performed in 11 patients with a good physical condition; no morbidity was reported and all of the patients were alive $\geqslant 15$ months later. Overall survival at 5 years was $18.2 \%$. Survival of the other 10 patients receiving chemotherapy instead of surgical resection was significantly poorer $(9.1 \%)$.

As an alternative to surgical resection, ablative radiotherapy was offered to patients with pulmonary malignant lesions for the treatment of oligometastatic disease. Encouraging data with local control rates of $>90 \%$ at 2 years can be achieved in patients with lung metastases arising from extrathoracic cancers [49]. Comparable results were reported for NSCLC patients with metastatic pulmonary lesions. DE Rose et al. [50] analysed 60 NSCLC patients with 90 lung lesions and technical or physical contraindication to surgical resection. Lung metastases were diagnosed by radiology; however, no histological data on these have been reported. Two patients experienced pulmonary grade 3 toxicity. The local control rate of $88.9 \%$ at 2 years was observed. RiCARDI et al. [51] treated 61 patients with one to three lung metastases, 34 of whom had a history of NSCLC. A local control rate was $88 \%$, and $66.5 \%$ of the patients had a 2 -year overall survival. Notably, histological conformation of the lung nodules was not present in $88.5 \%$ of the patients. In accordance to other series, the majority of lung metastases is diagnosed indirectly through an increase of the lesion diameter in computed tomographic images or by 2-fluoro-2-deoxy-D-glucose uptake during positron emission tomography (PET) [49]. In fact, the development of de novo pulmonary nodules is highly suspicious for metastases of a previously treated extrathoracic cancer (e.g. colorectal, renal, sarcoma). In NSCLC patients, the aforementioned obstacle to differentiate between a metastasis of the NSCLC, a metastasis of a separate solid tumour, or a secondary pulmonary primary cancer results in uncertain prognostic estimations. Nevertheless, SBRT of malignant lung lesions is a valuable technique for patients who seem to be inoperable due to target location or an impaired physical status. Therefore, a 
detailed histological clarification should be pursued to plan further therapeutic measures and to predict survival. Recently, LONDERo et al. [52] reviewed and compared the outcome following SBRT and surgery for the treatment of pulmonary metastases. 61 articles on surgery and 18 on SBRT were found to be eligible, each with cohorts of $>50$ patients. Even though a difference in short-term survival could not be demonstrated, data on long-term outcome suggest an advantage for surgery. Conclusively, the advantages of ease and repetitive application of SBRT, even in multiple bilateral or anatomically unfavourable locations must be balanced with radical surgical resection giving important information about histology and resection margin.

Radiofrequency ablation can be offered to patients as an alternative limited treatment for lung metastases. Mainly performed in patients who are functionally inoperable, a pre-treatment biopsy can prove the histology, and a complete and sustained target ablation was reported in up to $90 \%$ of the patients [53].

Cancer-specific survival of 5 years in patients with primary lung cancer and lung metastases reached $56.7 \%$ and $71 \%$, respectively, in a series reported by PICCHI et al. [54]. The comparative overall survival rates were $16.1 \%$ and $43.3 \%$, respectively. The reported poor overall survival rates illustrate that patients undergoing radiofrequency ablation merely suffer from multiple nonmalignant, but life-threatening cardiopulmonary or cardiac comorbidities.

To summarise, all three techniques should be considered as feasible ablative treatment options for lung (oligo) metastases taking into account their risks, advantages, the expected benefit and the individual patient status.

\section{Brain metastases}

$20-50 \%$ of the patients with NSCLC develop brain metastases in the course of their disease and median survival of $\leqslant 12$ months is expected from time of detection [8,55-57]. More than five decades ago whole-brain radiotherapy (WBRT) was applied as first-line therapy, although it was associated with a high rate of chronic neurological impairment [58]. In recent years, treatment strategies developed continuously and include surgery, radiotherapy and chemotherapy, which may be chosen depending on the location, extent and histology of the primary tumour, including investigation of molecular alterations and the physical status of the patient. Up to one-third of lung cancer patients are diagnosed with synchronous brain metastases, potentially amenable to an oligometastatic treatment concept $[24,59]$. First reports about radical surgical treatment of single brain metastases were reported in 1986 showing a favourable median survival of 33 months in patients with a radically treated primary tumour and no extracranial disease [60]. In 1990, PATChell et al. [61] conducted an early controlled randomised trial comparing surgery plus WBRT (36 Gy) to radiotherapy alone $(36 \mathrm{~Gy}$ ) for patients with isolated brain metastases. Local recurrence was less frequent in the surgical group (20\% versus 52\%) and patients survived significantly longer (40 weeks versus 15 weeks) with lesser neurofunctional restrictions. $77 \%$ of the patients in this series had a primary NSCLC. In contrast, MiNTz et al. [62] found a median survival of 6.3 months following radiation therapy only ( $30 \mathrm{~Gy}$ ) compared to 5.6 months following surgery in combination with radiation (30 Gy), The study failed to demonstrate a significant prognostic difference. A meta-analysis of comparative trials in patients with metastasised NSCLC to the brain found no differences in survival in between the two treatment regimens. However, a subgroup of younger patients with controlled primary disease and a singular metastasis were identified to profit from surgery [63]. In this meta-analysis, brain metastases derived from varying primary cancers.

Brain (oligo-) metastases in lung cancer have been analysed in many retrospective cohort studies. ZHANG et al. [64] recently evaluated 88 patients with NSCLC stage IV, of whom 18 had one to three brain metastases at initial diagnosis. Surgery was part of the treatment in seven out of 13 patients with a single metastasis. Patients with two or three lesions received stereotactic radiotherapy. Median survival reported was 55 months; 3-year survival was 60.8\%. FURÁK et al. [65] published a cohort of 65 lung cancer patients with either synchronous $(n=19)$ or metachronous $(n=46)$ brain metastases. All patients underwent surgery for lung primary and brain lesion both locations and WBRT with boost to the tumour resection bed was applied afterwards. Median survival of patients with synchronous and metachronous brain metastases was 18 months and 12 months, respectively. Cancer-related symptoms were identified as a poor prognostic factor. Another retrospective series with 103 patients was presented by BonETTE et al. in 2001 [66]. A 5 -year survival of $11 \%$ was reported for small, nodal-negative primary lung cancers displaying the most favourable prognosis, although it was not statistically significant. After brain metastasectomy, most patients in historical cohorts received additional WBRT. Owing to technical improvements in the field of radiotherapy, stereotactic radiotherapy has become an alternative treatment option after neurosurgical intervention, thus called stereotactic "radiosurgery" (SRS). It was suggested that SRS yields comparable outcome and local control rates to post-operative WBRT [67]. A randomised study with $>300$ patients (64\% with lung cancer) revealed that SRS (as a boost to the tumour) plus WBRT resulted in improved 
survival compared to WBRT alone [68]. In addition, a better post-interventional functional status, less neurophysiological impairment and less steroid application were observed [69, 70]. Consequently, subsequent clinical trials confirmed improved outcome after SRS with no significant difference in survival as compared to WBRT. The results of these controlled studies as well as those from retrospective literature reviews underline the significance of SRS as standard of care treatment for isolated brain metastases [71, 72]. Based upon these findings, current trials investigate the benefit of SRS for $\geqslant 10$ isolated brain metastases. However, patients in a potentially "curative" oligometastatic disease should not exceed three isolated brain metastases amenable to stereotactic ablative radiotherapy.

\section{Adrenal metastases}

Adrenal metastases can be found in up to $20 \%$ of the patients with NSCLC [7]. Most patients receive systemic treatment either due to a locally incurable disease or additional distant metastases. $~ 5 \%$ of the patients with operable lung cancer present with a single synchronous adrenal metastasis at diagnosis and may qualify for local ablative therapies $[73,74]$.

Surgical adrenalectomy can result in 5-year survival rates of $>25 \%$ in selected patients [75]. RAz et al. [76] examined 37 patients with isolated adrenal metastases. Adrenalectomy was performed in 20 patients with a 5 -year survival rate of $34 \%$, as compared to $0 \%$ in patients without adrenalectomy. Ipsilateral adrenal metastases and lack of mediastinal lymph node metastases were identified as favourable independent prognostic factors. The chronological appearance of the adrenal gland metastases (i.e. metachronous or synchronous) were not associated with the survival. LuKETich et al. [77] investigated the benefit of an adrenalectomy following adjuvant chemotherapy for synchronous adrenal metastases. Out of the 14 eligible patients, eight underwent adrenalectomy and six received only chemotherapy. Median survival of these eight surgical patients was 31 months compared to 8.5 months for patients who had exclusively medical treatment. Similar results were reported in a cohort of 13 patients analysed by ABDEL-RAHEEM et al. [78]. They observed improved survival rates of 19 months in patients treated with adjuvant chemotherapy following adrenalectomy compared to 14 months in patients without additional chemotherapy. Laparoscopic adrenalectomy is associated with a lower perioperative morbidity and a reduced hospital length of stay as compared to open surgery [79]. The decision for minimally invasive surgery should be based upon the tumour size and the technical resectability.

PARDO ARANDa et al. [80] investigated whether surgery should start with laparoscopic adrenalectomy or lung surgery. In 10 patients undergoing adrenalectomy first, the mean delay for lung surgery in this small cohort was 28 days. Therefore, it seems advisable to start with the treatment of the primary lung cancer to identify patients with mediastinal lymph node metastases harbouring poor survival and to avoid delay of lung surgery [76, 81]. Mazzella et al. [82] undertook extensive molecular assessment of resected primary and adrenal oligometastases in 20 patients. Mutational discordance between both locations were identified in $20 \%$ of the patients. However, the authors were not able to show a correlation with 5-year survival, which was $34 \%$. In conclusion, adrenalectomy is an appropriate and safe treatment modality for NSCLC patients with controlled primary lung cancer associated with increased survival of highly selected patients with the opportunity for pathological assessment of the metastasis $[77,78]$.

SBRT is an alternative approach to treat adrenal gland metastases. Mainly performed in physically impaired patients, it is associated with tolerable toxicity and a 1-year local control rate of $>80 \%$ in retrospective series [83-85]. SCORSETTI et al. [86] analysed 34 patients with adrenal metastases of different primary cancer, $64 \%$ of whom had NSCLC. The median follow-up was 41 months and the median freedom from local recurrence was 19 months. Holy et al. [87] examined 13 patients with primary lung cancer and adrenal metastases treated with curative-intent surgery, combined with chemoradiotherapy. Median progression-free survival and overall survival of these patients were 12 and 23 months, respectively. A comparable cohort of patients undergoing palliative intent SBRT for pain relief died within 6 months. The most reported toxicity was mild nausea, whereas adrenal or renal insufficiencies were not observed.

The aforementioned data suggest that surgery or SBRT are suitable local ablative therapy options for the treatment of adrenal oligometastases in selected patients with NSCLC.

\section{Bone metastases}

Few studies have analysed the potentially curative treatment of patients with isolated bone metastases of NSCLC without other extrapulmonary tumour burden. ZHANG and GoNG [88] investigated 168 patients with bone metastases of NSCLC treated from 2014 to 2015. 2-year survival of these patients was only $13 \%$. Singular metastases, pulmonary stage I/II and a histology of a squamous cell carcinoma were identified as favourable prognostic factors. The treatment regimen with chemotherapy, radiotherapy and bisphosphonates did not correlate with prognosis. GRIFFIOEN et al. [89] reported on 61 patients with one to 
three synchronous metastases and radical-intent treatment for all locations. Bone metastases were found in $11(18 \%)$ patients and were identified as a negative prognostic factor. TAKAHASHI et al. [90] analysed 41 patients with curative intent treatment of both pulmonary primary NSCLC and bone metastasis. In $49 \%$ of the patients, more than one bone lesion was identified. Surgery was performed in nine patients; all the other patients were treated with chemotherapy and/or tyrosine kinase therapy. Radiotherapy was the primary treatment option for the bone metastases. Overall and progression-free survival in the lung surgery group were $66.7 \%$ and $55.6 \%$, respectively. Resection of the primary lung tumour was identified as predictive for overall survival and progression-free survival in the multivariate analysis. Bone oligometastases are rarely resected surgically, as they often occur in the spine and are therefore better accessible for radiotherapy. HisHida et al. [91] retrospectively reviewed data of 768 surgical lung cancer patients of whom 18 patients developed a single bone metastasis. Only one of them had a surgical resection of a rib metastasis and is still alive 9.6 years following surgery. A systematic review by WOOD et al. [92] focused on the impact of surgical resection of bone metastases, analysing 45 reports including patients with oligometastatic disease of heterogeneous primary cancers and a mixed percentage of lung cancer. A benefit of surgical resection was only evident in patients with metastases of the long bones or the pelvis/acetabulum.

\section{Other extrathoracic locations}

Only a paucity of case studies evaluated the role of local ablative therapy in other localised extrathoracic oligometastases. One to three liver metastases per patient were treated by SBRT in a multi-institutional phase I/II trial by RUSTHOVEN et al. [93], and patients with various primary cancers and differing previous therapies were included ( $21 \%$ lung cancer). Overall local control for all 28 lesions was $94 \%$, and $100 \%$ for lesions $<3 \mathrm{~cm}$ in diameter. However, primary lung cancer was associated with poor outcome. Control rates of $74-91 \%$ at 2 years were shown in cohorts with one to three liver metastases. Nevertheless, survival was reported between $62 \%$ and $70 \%$ as far as indicated [94-96].

A systematic review by DeLuzio et al. [97] focused on tumour patients with pancreatic oligometastases treated between 1970 and 2014. They identified 32 patients, of whom 16 had NSCLC as a primary tumour. Curative intent surgery was performed in 15 patients with a trend towards increased survival compared to palliative therapy or salvage procedures ( $21 \%$ versus $8 \%$ at 5 years). Lesions that were found incidentally during abdominal staging were associated with better outcome than symptomatic metastases. SALAH et al. [98] conducted a literature research for solitary extra-adrenal extracranial metastases in NSCLC in 2012 and identified 51 articles with 75 patients. Finally, 62 cases matched the eligibility criteria and information on the treatment of both primary lung cancer and metastases were available. The most common metastatic sites were bone $(n=13)$, liver $(n=9)$, kidney $(n=7)$ and spleen $(n=6)$. Survival data for the latter two are not shown; however, all of these patients were from different single-case reports. 5-year survival for the entire cohort was $50 \%$, and N2 or N3 disease in the primary lung cancer was identified as a negative prognostic factor. In small case series, adrenal, skin and axillary nodal metastases achieved prolonged survival of $>5$ years after resection [99].

Retrospective data from NSCLC patients with localised metastases in uncommon locations as described earlier suggests that a locally ablative approach may be a feasible therapeutic option in an individual oligometastatic treatment plan in highly selected patients.

\section{The role of systemic treatment of oligometastatic disease}

Systemic therapy is applied to most patients during their treatment course for oligometastatic NSCLC; however, varying data exist from retrospective studies. A meta-analysis including 54 series on oligometastatic lung cancer found that chemotherapy was given during the course of the disease in $61.2 \%$ of the patients with metachronous and in $75 \%$ of patients with synchronous oligometastases. Targeted therapies were administered in only $5 \%$ of the patients [17]. In contrast, chemotherapy was applied as part of the primary lung cancer treatment in only $17.7 \%$ of the patients in the meta-analysis by AsHWORTH et al. [24]. The role of novel immunomodulatory therapies in the context of oligometastatic disease needs to be further elucidated. So far, there has been one ongoing phase-II trial (NCT03705403) investigating the benefit of immunotherapy in combination with SBRT compared to the standard of care in patients with a limited tumour load, defined as one to five oligometastases [100]. It is to be expected that future strategies for stage IV NSCLC patients in an oligometastatic state will comprise both local ablative and personalised systemic modalities depending on multidisciplinary decision.

\section{Current patient selection and prognostic factors}

The identification of patients suitable for the "oligometastatic" concept of local ablative treatment of limited tumour manifestations is of utmost importance. Stratification of potentially eligible patients with prognostic factors associated with increased survival may help to define the beneficial subgroup. In 2014, a 
meta-analysis of oligometastatic patient data was performed by AsHwORTH et al. [24] to identify potential prognostic factors. 757 patients with one to five metastases were included, all of them with curative intent lung cancer treatment. 5-year survival of the entire cohort was 29\%. Synchronous metastases and mediastinal lymph node involvement were associated with poor prognosis. As a consequence, the authors proposed a risk stratification model of stage IV patients to identify potentially long-term survivors. Factors associated with a better prognosis were metachronous development and nodal negative primary. In patients with brain oligometastases, disease-free survival, performance status and the nodal status of the primary tumour have been demonstrated repetitively as prognostic factors [101].

Multivariate data analysis of 94 oligometastatic patients with various extrathoracic singular metastases demonstrated a small tumour size, a negative mediastinal and hilar lymph node status, younger age, induction treatment and adenocarcinoma histology as significant favourable prognostic factors. No differences in survival were found concerning the type of local ablative therapy (surgery versus radiotherapy) [102]. N2-disease in the lung primary tumour has been discussed regularly as the strongest negative predictor for survival and accurate mediastinal staging has been requested in the current guidelines [11]. Based on their own results, JoHnson et al. [103] recommended invasive mediastinal staging to exclude N2-disease. Their series demonstrated significant difference in survival among patients with N0 (58\% at 5 years) and N2 disease (0\%). As an additional prerequisite limited tumour burden, the individual possibility of local ablative therapy (either surgery or SBRT), and regular interdisciplinary discussions are strongly recommended by international oncological societies. Detailed histopathological workup for potential druggable targets should be considered for an additional chemo-/immunetherapy treatment $[12,104]$.

Based on the current evidence, we recommend the following strategy for a physically fit patient who is assumed to have "oligometastatic" disease:

1) Staging procedure should include brain magnetic resonance imaging (MRI) and PET.

2) Suspicious mediastinal lymph nodes should be investigated by invasive mediastinal staging with endobronchial ultrasound guided needle aspiration. Inconsistent findings should be further clarified by stepwise diagnostic approaches (e.g. mediastinoscopy, thoracoscopy).

3) Primary treatment should include anatomical resection (e.g. lobectomy, bilobectomy, pneumonectomy) and systematic mediastinal and hilar lymph node dissection.

4) Distant metastases should not exceed one to three lesions, all of them amenable to local ablative therapy.

5) Specific situations:

- For simultaneous contralateral isolated lung lesions: the possibility of a secondary (early-stage) lung cancer should be taken into consideration and radical treatment should thus be preferred;

- Metachronous extrathoracic metastases should undergo local ablative therapy if recurrence of the primary lung cancer and metastatic disease progression is ruled out in restaging by PET and brain MRI.

6) Further (adjuvant/additive) therapy, chronology:

- Interdisciplinary discussion for systemic therapies should take into account patient physical status, individual course after local ablative therapy and specific histological features of the tumour. Molecular testing of druggable receptors and immune pathways is mandatory;

- Cis-platinum-based combination chemotherapy should be integrated into the treatment course and follow the current recommendations for the treatment of NSCLC in nonmetastasised disease.

\section{Ongoing clinical trials}

Current evidence from many retrospective and few phase II trials suggest that local ablative therapy in stage IV patients with limited metastatic load may be associated with favourable long-term survival compared to patients with a disseminated disease [105, 106]. A randomised trial by GomEz et al. [106] found improved progression-free and overall survival if local consolidative therapy (LCT) was administered to patients with oligometastases following standard front-line systemic therapy. Comparative groups received maintenance therapy or observation only. Recruitment was terminated early by the data safety monitoring board after 49 patients had been randomised due to a very high probability of superiority of the LCT arm. Patients receiving conventional systemic therapy or targeted epidermal growth factor or anaplastic lymphoma kinase inhibitor therapy were included into the study. A subgroup analysis was not possible due to the small cohort, and investigation into patients' individual prognostic conditions was not possible. The findings indicate that LCT should be integrated into the treatment course of patients with localised extrathoracic tumour burden. The results of ongoing prospective trials addressing oligometastatic disease are eagerly awaited. A literature search (conducted July 1, 2020, ClinicalTrials.gov) identified eight studies after exclusion of trials that focused on cancers other than NSCLC or omitted local ablative therapy 
for either primary or metastatic lesion or both (table 1). Only two trials (NCT03965468, NCT03827577) include surgical resection of primary/metastases as an optional treatment modality; however, recruitment is still ongoing. One trial was closed due to slow accrual (NCT02054819). РетTY et al. [107] (NCT01185639) published their results after enrolment of 27 patients. Overall survival was 28.4 months. Based on these encouraging results, the authors concluded the feasibility of their study concept and proposed chemotherapy followed by local ablative radiotherapy.

TABLE 1 Clinical trials investigating oligometastatic disease

\begin{tabular}{|c|c|c|c|c|}
\hline Identifier & Title & Description & Allocation & Status \\
\hline NCT03965468 & $\begin{array}{c}\text { Immunotherapy, } \\
\text { chemotherapy, radiotherapy } \\
\text { and surgery for } \\
\text { synchronous } \\
\text { oligo-metastatic NSCLC }\end{array}$ & $\begin{array}{c}\text { Immunotherapy, } \\
\text { chemotherapy plus } \\
\text { stereotactic radiotherapy to } \\
\text { synchronous } \\
\text { oligo-metastases followed by } \\
\text { definitive surgery or } \\
\text { radiotherapy to primary } \\
\text { NSCLC }\end{array}$ & & Recruiting \\
\hline NCT03827577 & $\begin{array}{c}\text { OMEGA, local ablative } \\
\text { therapy in oligometastatic } \\
\text { NSCLC }\end{array}$ & $\begin{array}{l}\text { Resection of primary NSCLC } \\
\text { plus local ablative therapy to } \\
\text { all metastases versus } \\
\text { standard-of-care } \\
\text { chemotherapy }\end{array}$ & Randomised & Recruiting \\
\hline NCT03275597 & $\begin{array}{c}\text { Phase lb study of } \\
\text { stereotactic body } \\
\text { radiotherapy (SBRT) in } \\
\text { oligometastatic non-small } \\
\text { lung cancer (NSCLC) with } \\
\text { dual immune checkpoint } \\
\text { inhibition }\end{array}$ & $\begin{array}{l}\text { SBRT followed by combined } \\
\text { durvalumab and } \\
\text { tremelimumab }\end{array}$ & & Recruiting \\
\hline NCT03119519 & $\begin{array}{l}\text { Local non-salvage } \\
\text { radiotherapy for } \\
\text { synchronous } \\
\text { oligometastatic } \\
\text { non-small-cell lung cancer }\end{array}$ & $\begin{array}{l}\text { Chemotherapy plus local } \\
\text { definitive radiotherapy to } \\
\text { primary and } \\
\text { oligo-metastases versus } \\
\text { standard-of-care chemo-/ } \\
\text { targeted-therapy }\end{array}$ & Randomised & Recruiting \\
\hline NСT02975609 & $\begin{array}{l}\text { Phase II trial of SBRT } \\
\text { compared with } \\
\text { conventional radiotherapy } \\
\text { for oligometastatic } \\
\text { non-small cell lung cancer }\end{array}$ & $\begin{array}{l}\text { Chemotherapy plus SBRT } \\
\text { versus chemotherapy plus } \\
\text { conventional fractionated } \\
\text { radiotherapy to primary and } \\
\text { all metastatic sites }\end{array}$ & Randomised & $\begin{array}{l}\text { Not yet } \\
\text { recruiting }\end{array}$ \\
\hline NСT02417662 & $\begin{array}{c}\text { Stereotactic ablative } \\
\text { radiotherapy for } \\
\text { oligometastatic non-small } \\
\text { cell lung cancer }\end{array}$ & $\begin{array}{l}\text { Patients will be randomised } \\
\text { to receive either standard } \\
\text { chemotherapy treatment } \\
\text { alone or standard treatment } \\
\text { with conventional } \\
\text { radiotherapy and SABR }\end{array}$ & Randomised & Recruiting \\
\hline NCT02054819 & $\begin{array}{l}\text { Treating NSCLC minimal } \\
\text { stage IV with curative intent }\end{array}$ & $\begin{array}{l}\text { Platinum-based } \\
\text { chemotherapy with } \\
\text { concurrent radiation therapy } \\
\text { to the primary tumour and } \\
\text { identified mediastinal lymph } \\
\text { nodal metastatic drainage. } \\
\text { Local curative radiation will } \\
\text { then target the } \\
\text { oligometastatic tumour sites }\end{array}$ & & $\begin{array}{c}\text { Terminated } \\
\text { (low accrual) }\end{array}$ \\
\hline NCT01185639 & $\begin{array}{l}\text { Stereotactic body radiation } \\
\text { therapy (SBRT) in } \\
\text { metastatic non-small cell } \\
\text { lung cancer }\end{array}$ & $\begin{array}{l}\text { Chemotherapy followed by } \\
\text { local ablative radiotherapy to } \\
\text { all metastatic lesions }\end{array}$ & & Completed \\
\hline
\end{tabular}

NSCLC: nonsmall cell lung cancer; SBRT: stereotactic body radiotherapy; SABR: stereotactic ablative radiotherapy. 


\section{Conclusion and future directions}

Significant advances in the diagnosis and treatment of patients with NSCLC resulted in prolonged survival of the patients with metastatic disease. The observation that patients with a limited metastatic burden have a favourable survival paved the way for the inclusion of local ablative treatment options.

A large number of retrospective studies are available; nevertheless, definition of oligometastatic disease varies in terms of location, number of metastases and treatment modalities. Ongoing trials investigate different local ablative therapies. Inclusion of targeted therapies and immunemodulatory drugs are currently analysed for their potential benefit in this subgroup of NSCLC patients.

As long as these results are pending and prognostic factors have not been validated in larger cohorts of patients, actual clinical guidelines recommend interdisciplinary individual treatment. Evidence from the literature suggests that an aggressive local approach to both the primary lung cancer and organ metastases should be an integral part of the multimodal treatment. Large trials comparing surgery and radiotherapy have not been conducted yet. Thus, individual patient characteristics, extent and location of the primary lung cancer and the metastases, as well as the interval of disease progression (synchronous or metachronous) have to be taken into account, particularly. In accordance to Ashworth's risk stratification scheme, we expect the best results following local ablative therapy for patients with oligometastatic lung cancer lacking N2 lymph node involvement and fewer than four metachronous organ metastases.

Conflict of interest: None declared.

\section{References}

1 Miller KD, Siegel RL, Lin CC, et al. Cancer treatment and survivorship statistics, 2016. CA Cancer J Clin 2016; 66: 271-289.

2 Ferlay J, Soerjomataram I, Dikshit R, et al. Cancer incidence and mortality worldwide: sources, methods and major patterns in GLOBOCAN 2012. Int J Cancer 2015; 136: E359-E386.

3 Meza R, Meernik C, Jeon J, et al. Lung cancer incidence trends by gender, race and histology in the United States, 1973-2010. PLoS One 2015; 10: e0121323.

4 Morgensztern D, Ng SH, Gao F, et al. Trends in stage distribution for patients with non-small cell lung cancer: a National Cancer Database survey. J Thorac Oncol 2010; 5: 29-33.

5 Rami-Porta R, Bolejack V, Giroux DJ, et al. The IASLC lung cancer staging project: the new database to inform the eighth edition of the TNM classification of lung cancer. J Thorac Oncol 2014; 9: 1618-1624.

6 Chansky K, Detterbeck FC, Nicholson AG, et al. The IASLC Lung Cancer Staging Project: External Validation of the Revision of the TNM Stage Groupings in the Eighth Edition of the TNM Classification of Lung Cancer. J Thorac Oncol 2017; 12: 1109-1121.

7 Eberhardt WE, Mitchell A, Crowley J, et al. The IASLC Lung Cancer Staging Project: Proposals for the Revision of the M Descriptors in the Forthcoming Eighth Edition of the TNM Classification of Lung Cancer. J Thorac Oncol 2015; 10: 1515-1522

8 Riihimäki M, Hemminki A, Fallah M, et al. Metastatic sites and survival in lung cancer. Lung Cancer 2014; 86: 78-84.

9 Stephens SJ, Moravan MJ, Salama JK. Managing patients with oligometastatic non-small-cell lung cancer. J Oncol Pract 2018; 14: 23-31.

10 Torok JA, Gu L, Tandberg DJ, et al. Patterns of distant metastases after surgical management of non-small-cell lung cancer. Clin Lung Cancer 2017; 18: e57-e70.

11 Kozower BD, Larner JM, Detterbeck FC, et al. Special treatment issues in non-small cell lung cancer: diagnosis and management of lung cancer, 3rd ed: American College of Chest Physicians evidence-based clinical practice guidelines. Chest 2013; 143: Suppl. 5, e369S-e399S.

12 Majem M, Juan O, Insa A, et al. SEOM clinical guidelines for the treatment of non-small cell lung cancer (2018). Clin Transl Oncol 2019; 21: 3-17.

13 Novello S, Barlesi F, Califano R, et al. Metastatic non-small-cell lung cancer: ESMO Clinical Practice Guidelines for diagnosis, treatment and follow-up. Ann Oncol 2016; 27: Suppl. 5, v1-v27.

14 Li D, Zhu X, Wang $\mathrm{H}$, et al. Should aggressive thoracic therapy be performed in patients with synchronous oligometastatic non-small cell lung cancer? A meta-analysis. J Thorac Dis 2017; 9: 310-317.

15 Juan O, Popat S. Ablative therapy for oligometastatic non-small cell lung cancer. Clin Lung Cancer 2017; 18: 595-606.

16 Pfannschmidt J, Dienemann H. Surgical treatment of oligometastatic non-small cell lung cancer. Lung Cancer 2010; 69: 251-258.

17 Schanne DH, Heitmann J, Guckenberger M, et al. Evolution of treatment strategies for oligometastatic NSCLC patients - a systematic review of the literature. Cancer Treat Rev 2019; 80: 101892.

18 Hellman S, Weichselbaum RR. Oligometastases. J Clin Oncol 1995; 13: 8-10.

19 Paget S. The distribution of secondary growths in cancer of the breast. 1889. Cancer Metastasis Rev 1989; 8: 98-101.

20 Milano MT, Katz AW, Zhang $\mathrm{H}$, et al. Oligometastases treated with stereotactic body radiotherapy: long-term follow-up of prospective study. Int J Radiat Oncol Biol Phys 2012; 83: 878-886.

21 Villarreal-Garza C, de la Mata D, Zavala DG, et al. Aggressive treatment of primary tumor in patients with non-small-cell lung cancer and exclusively brain metastases. Clin Lung Cancer 2013; 14: 6-13.

22 Pastorino U, Buyse M, Friedel G, et al. Long-term results of lung metastasectomy: prognostic analyses based on 5206 cases. J Thorac Cardiovasc Surg 1997; 113: 37-49. 
Niibe Y, Hayakawa K. Oligometastases and oligo-recurrence: the new era of cancer therapy. Jpn J Clin Oncol 2010; 40: 107-111.

Ashworth AB, Senan S, Palma DA, et al. An individual patient data metaanalysis of outcomes and prognostic factors after treatment of oligometastatic non-small-cell lung cancer. Clin Lung Cancer 2014; 15: 346-355.

Patchell RA, Cirrincione C, Thaler HT, et al. Single brain metastases: surgery plus radiation or radiation alone. Neurology 1986; 36: 447-453.

Tummarello D, Porfiri E, Rychlicki F, et al. Non-small cell lung cancer. Neuroresection of the solitary intracranial metastasis followed by radiochemotherapy. Cancer 1985; 56: 2569-2572.

Magilligan DJ Jr, Duvernoy C, Malik G, et al. Surgical approach to lung cancer with solitary cerebral metastasis: twenty-five years' experience. Ann Thorac Surg 1986; 42: 360-364.

Tönnies M, Pfannschmidt J, Bauer TT, et al. Metastasectomy for synchronous solitary non-small cell lung cancer metastases. Ann Thorac Surg 2014; 98: 249-256.

Collaud S, Stahel R, Inci I, et al. Survival of patients treated surgically for synchronous single-organ metastatic NSCLC and advanced pathologic TN stage. Lung Cancer 2012; 78: 234-238.

Timmerman RD, Bizekis CS, Pass HI, et al. Local surgical, ablative, and radiation treatment of metastases. CA Cancer J Clin 2009; 59: 145-170.

Churilla TM, Chowdhury IH, Handorf E, et al. Comparison of local control of brain metastases with stereotactic radiosurgery $v s$ surgical resection: a secondary analysis of a randomized clinical trial. JAMA Oncol 2019; 5: 243-247.

Lewis SL, Porceddu S, Nakamura N, et al. Definitive stereotactic body radiotherapy (SBRT) for extracranial oligometastases: an international survey of $>1000$ radiation oncologists. Am J Clin Oncol 2017; 40: 418-422.

Lodeweges JE, Klinkenberg TJ, Ubbels JF, et al. Long-term outcome of surgery or stereotactic radiotherapy for lung oligometastases. J Thorac Oncol 2017; 12: 1442-1445.

Lencioni R, Crocetti L, Cioni R, et al. Response to radiofrequency ablation of pulmonary tumours: a prospective, intention-to-treat, multicentre clinical trial (the RAPTURE study). Lancet Oncol 2008; 9: 621-628.

Simon CJ, Dupuy DE, DiPetrillo TA, et al. Pulmonary radiofrequency ablation: long-term safety and efficacy in 153 patients. Radiology 2007; 243: 268-275.

Hiraki T, Kanazawa S. Lung radiofrequency ablation: potential as a therapy to oligometastasis and oligorecurrence. Pulm Med 2012; 2012: 196173.

Hasegawa T, Yamakado K, Nakatsuka A, et al. Unresectable adrenal metastases: clinical outcomes of radiofrequency ablation. Radiology 2015; 277: 584-593.

Weber B, Liu M, Sobkin P, et al. Successful treatment of hepatic oligometastases with stereotactic ablative radiotherapy and radiofrequency ablation in an anaplastic lymphoma kinase fusion-positive lung cancer patient. $J$ Med Radiat Sci 2016; 63: 67-70.

Rami-Porta R, Ball D, Crowley J, et al. The IASLC Lung Cancer Staging Project: proposals for the revision of the $\mathrm{T}$ descriptors in the forthcoming (seventh) edition of the TNM classification for lung cancer. $J$ Thorac Oncol 2007; 2: 593-602.

Rami-Porta R, Bolejack V, Crowley J, et al. The IASLC Lung Cancer Staging Project: proposals for the revisions of the T descriptors in the forthcoming eighth edition of the TNM classification for lung cancer. $J$ Thorac Oncol 2015; 10: 990-1003.

Martini N, Melamed MR. Multiple primary lung cancers. J Thorac Cardiovasc Surg 1975; 70: 606-612.

Girard N, Deshpande C, Lau C, et al. Comprehensive histologic assessment helps to differentiate multiple lung primary nonsmall cell carcinomas from metastases. Am J Surg Pathol 2009; 33: 1752-1764.

Liu Y, Zhang J, Li L, et al. Genomic heterogeneity of multiple synchronous lung cancer. Nat Commun 2016; 7: 13200.

Warth A, Macher-Goeppinger S, Muley T, et al. Clonality of multifocal nonsmall cell lung cancer: implications for staging and therapy. Eur Respir J 2012; 39: 1437-1442.

Fabian T, Bryant AS, Mouhlas AL, et al. Survival after resection of synchronous non-small cell lung cancer. $J$ Thorac Cardiovasc Surg 2011; 142: 547-553.

De Leyn P, Moons J, Vansteenkiste J, et al. Survival after resection of synchronous bilateral lung cancer. Eur J Cardiothorac Surg 2008; 34: 1215-1222.

Voltolini L, Rapicetta C, Luzzi L, et al. Surgical treatment of synchronous multiple lung cancer located in a different lobe or lung: high survival in node-negative subgroup. Eur J Cardiothorac Surg 2010; 37: 1198-1204.

$\mathrm{He}$ J, Li Y, An J, et al. Surgical treatment in non-small cell lung cancer with pulmonary oligometastasis. World J Surg Oncol 2017; 15: 36.

Filippi AR, Badellino S, Guarneri A, et al. Outcomes of single fraction stereotactic ablative radiotherapy for lung metastases. Technol Cancer Res Treat 2014; 13: 37-45.

De Rose F, Cozzi L, Navarria P, et al. Clinical outcome of stereotactic ablative body radiotherapy for lung metastatic lesions in non-small cell lung cancer oligometastatic patients. Clin Oncol 2016; 28: 13-20. 2012; 75: 77-81.

Londero F, Grossi W, Morelli A, et al. Surgery versus stereotactic radiotherapy for treatment of pulmonary metastases. A systematic review of literature. Future Sci OA 2020; 6: FSO471.

Pereira PL, Masala S, Cardiovascular and Interventional Radiological Society of Europe (CIRSE). Standards of practice: guidelines for thermal ablation of primary and secondary lung tumors. Cardiovasc Intervent Radiol 2012; 35: 247-254.

Picchi SG, Lassandro G, Bianco A, et al. RFA of primary and metastatic lung tumors: long-term results. Med Oncol 2020; 37: 35 . groups, and prognosis. J Clin Oncol 1988; 6: 1474-1480.

Khalifa J, Amini A, Popat S, et al. Brain metastases from NSCLC: radiation therapy in the era of targeted therapies. J Thorac Oncol 2016; 11: 1627-1643.

Sperduto PW, Yang TJ, Beal K, et al. Estimating survival in patients with lung cancer and brain metastases: an update of the graded prognostic assessment for lung cancer using molecular markers (Lung-molGPA). JAMA Oncol 2017; 3: 827-831. 
Brown PD, Ahluwalia MS, Khan OH, et al. Whole-brain radiotherapy for brain metastases: evolution or revolution? J Clin Oncol 2018; 36: 483-491.

Quint LE, Tummala S, Brisson LJ, et al. Distribution of distant metastases from newly diagnosed non-small cell lung cancer. Ann Thorac Surg 1996; 62: 246-250.

Mandell L, Hilaris B, Sullivan M, et al. The treatment of single brain metastasis from non-oat cell lung carcinoma. Surgery and radiation versus radiation therapy alone. Cancer 1986; 58: 641-649.

Patchell RA, Tibbs PA, Walsh JW, et al. A randomized trial of surgery in the treatment of single metastases to the brain. N Engl J Med 1990; 322: 494-500.

Mintz AH, Kestle J, Rathbone MP, et al. A randomized trial to assess the efficacy of surgery in addition to radiotherapy in patients with a single cerebral metastasis. Cancer 1996; 78: 1470-1476.

Hart MG, Grant R, Walker M, et al. Surgical resection and whole brain radiation therapy versus whole brain radiation therapy alone for single brain metastases. Cochrane Database Syst Rev 2005; 2005: CD003292.

Zhang C, Wang L, Li W, et al. Surgical outcomes of stage IV non-small cell lung cancer: a single-center experience. J Thorac Dis 2019; 11: 5463-5473.

Furák J, Troján I, Szöke T, et al. Lung cancer and its operable brain metastasis: survival rate and staging problems. Ann Thorac Surg 2005; 79: 241-247.

Bonnette P, Puyo P, Gabriel C, et al. Surgical management of non-small cell lung cancer with synchronous brain metastases. Chest 2001; 119: 1469-1475.

Lamba N, Muskens IS, DiRisio AC, et al. Stereotactic radiosurgery versus whole-brain radiotherapy after intracranial metastasis resection: a systematic review and meta-analysis. Radiat Oncol 2017; 12: 106.

Andrews DW, Scott CB, Sperduto PW, et al. Whole brain radiation therapy with or without stereotactic radiosurgery boost for patients with one to three brain metastases: phase III results of the RTOG 9508 randomised trial. Lancet 2004; 363: 1665-1672.

Patil CG, Pricola K, Sarmiento JM, et al. Whole brain radiation therapy (WBRT) alone versus WBRT and radiosurgery for the treatment of brain metastases. Cochrane Database Syst Rev 2017; 9: CD006121.

Aoyama H, Tago M, Kato N, et al. Neurocognitive function of patients with brain metastasis who received either whole brain radiotherapy plus stereotactic radiosurgery or radiosurgery alone. Int J Radiat Oncol Biol Phys 2007; 68: 1388-1395.

El Shafie RA, Dresel T, Weber D, et al. Stereotactic cavity irradiation or whole-brain radiotherapy following brain metastases resection - outcome, prognostic factors, and recurrence patterns. Front Oncol 2020; 10: 693.

Brown PD, Jaeckle K, Ballman KV, et al. Effect of radiosurgery alone $v$ s radiosurgery with whole brain radiation therapy on cognitive function in patients with 1 to 3 brain metastases: a randomized clinical trial. JAMA 2016; 316: 401-409.

Ettinghausen SE, Burt ME. Prospective evaluation of unilateral adrenal masses in patients with operable non-small-cell lung cancer. J Clin Oncol 1991; 9: 1462-1466.

Porte HL, Roumilhac D, Graziana JP, et al. Adrenalectomy for a solitary adrenal metastasis from lung cancer. Ann Thorac Surg 1998; 65: 331-335.

Tanvetyanon T, Robinson LA, Schell MJ, et al. Outcomes of adrenalectomy for isolated synchronous versus metachronous adrenal metastases in non-small-cell lung cancer: a systematic review and pooled analysis. J Clin Oncol 2008; 26: 1142-1147.

Raz DJ, Lanuti M, Gaissert HC, et al. Outcomes of patients with isolated adrenal metastasis from non-small cell lung carcinoma. Ann Thorac Surg 2011; 92: 1788-1792.

Luketich JD, Burt ME. Does resection of adrenal metastases from non-small cell lung cancer improve survival? Ann Thorac Surg 1996; 62: 1614-1616.

Abdel-Raheem MM, Potti A, Becker WK, et al. Late adrenal metastasis in operable non-small-cell lung carcinoma. Am J Clin Oncol 2002; 25: 81-83.

Dudley NE, Harrison BJ. Comparison of open posterior versus transperitoneal laparoscopic adrenalectomy. $\mathrm{Br} J$ Surg 1999; 86: 656-660.

Pardo Aranda F, Larrañaga Blanc I, Rivero Déniz J, et al. Surgical treatment of lung cancer with synchronous adrenal metastases: adrenalectomy first. Cir Esp 2017; 95: 97-101.

Gao XL, Zhang KW, Tang MB, et al. Pooled analysis for surgical treatment for isolated adrenal metastasis and non-small cell lung cancer. Interact Cardiovasc Thorac Surg 2017; 24: 1-7.

Mazzella A, Loi M, Mansuet-Lupo A, et al. Clinical characteristics, molecular phenotyping, and management of isolated adrenal metastases from lung cancer. Clin Lung Cancer 2019; 20: 405-411.

Figura NB, Oliver DE, Mohammadi H, et al. Novel dose escalation approaches for stereotactic body radiotherapy to adrenal oligometastases: a single-institution experience. Am J Clin Oncol 2020; 43: 107-114.

König L, Häfner MF, Katayama S, et al. Stereotactic body radiotherapy (SBRT) for adrenal metastases of oligometastatic or oligoprogressive tumor patients. Radiat Oncol 2020; 15: 30. radiation therapy (SBRT) of adrenal gland metastases. BMC Cancer 2020; 20: 536.

Scorsetti M, Alongi F, Filippi AR, et al. Long-term local control achieved after hypofractionated stereotactic body radiotherapy for adrenal gland metastases: a retrospective analysis of 34 patients. Acta Oncol 2012; 51: 618-623.

Holy R, Piroth M, Pinkawa M, et al. Stereotactic body radiation therapy (SBRT) for treatment of adrenal gland metastases from non-small cell lung cancer. Strahlenther Onkol 2011; 187: 245-251.

Zhang L, Gong Z. Clinical characteristics and prognostic factors in bone metastases from lung cancer. Med Sci Monit 2017; 23: 4087-4094.

Griffioen GH, Toguri D, Dahele M, et al. Radical treatment of synchronous oligometastatic non-small cell lung carcinoma (NSCLC): patient outcomes and prognostic factors. Lung Cancer 2013; 82: 95-102.

Takahashi Y, Adachi H, Mizukami Y, et al. Patient outcomes post-pulmonary resection for synchronous bone-metastatic non-small cell lung cancer. J Thorac Dis 2019; 11: 3836-3845.

Hishida T, Yoshida J, Aokage K, et al. Postoperative oligo-recurrence of non-small-cell lung cancer: clinica features and survival. Eur J Cardiothorac Surg 2016; 49: 847-853.

Wood TJ, Racano A, Yeung H, et al. Surgical management of bone metastases: quality of evidence and systematic review. Ann Surg Oncol 2014; 21: 4081-4089. 

therapy for liver metastases. J Clin Oncol 2009; 27: 1572-1578.

94 Méndez Romero A, Wunderink W, Hussain SM, et al. Stereotactic body radiation therapy for primary and metastatic liver tumors: a single institution phase I-II study. Acta Oncol 2006; 45: 831-837.

95 Ambrosino G, Polistina F, Costantin G, et al. Image-guided robotic stereotactic radiosurgery for unresectable liver metastases: preliminary results. Anticancer Res 2009; 29: 3381-3384.

96 Scorsetti M, Arcangeli S, Tozzi A, et al. Is stereotactic body radiation therapy an attractive option for unresectable liver metastases? A preliminary report from a phase 2 trial. Int J Radiat Oncol Biol Phys 2013; 86 336-342.

97 DeLuzio MR, Moores C, Dhamija A, et al. Resection of oligometastatic lung cancer to the pancreas may yield a survival benefit in select patients - a systematic review. Pancreatology 2015; 15: 456-462.

98 Salah S, Tanvetyanon T, Abbasi S. Metastatectomy for extra-cranial extra-adrenal non-small cell lung cancer solitary metastases: systematic review and analysis of reported cases. Lung Cancer 2012; 75: 9-14.

99 Ambrogi V, Tonini G, Mineo TC. Prolonged survival after extracranial metastasectomy from synchronous resectable lung cancer. Ann Surg Oncol 2001; 8: 663-666.

100 Lieverse RIY, Van Limbergen EJ, Oberije CJG, et al. Stereotactic ablative body radiotherapy (SABR) combined with immunotherapy (L19-IL2) versus standard of care in stage IV NSCLC patients, ImmunoSABR: a multicentre, randomised controlled open-label phase II trial. BMC Cancer 2020; 20: 557.

101 Suzuki H, Yoshino I. Approach for oligometastasis in non-small cell lung cancer. Gen Thorac Cardiovasc Surg 2016; 64: 192-196.

102 Mordant P, Arame A, De Dominicis F, et al. Which metastasis management allows long-term survival of synchronous solitary M1b non-small cell lung cancer? Eur J Cardiothorac Surg 2012; 41: 617-622.

103 Johnson KK, Rosen JE, Salazar MC, et al. Outcomes of a highly selective surgical approach to oligometastatic lung cancer. Ann Thorac Surg 2016; 102: 1166-1171.

104 Planchard D, Popat S, Kerr K, et al. Metastatic non-small cell lung cancer: ESMO clinical practice guidelines for diagnosis, treatment and follow-up. Ann Oncol 2018; 29: Suppl. 4, iv192-iv237.

105 De Ruysscher D, Wanders R, Hendriks LE, et al. Progression-free survival and overall survival beyond 5 years of NSCLC patients with synchronous oligometastases treated in a prospective phase II trial (NCT 01282450). J Thorac Oncol 2018; 13: 1958-1961.

106 Gomez DR, Tang C, Zhang J, et al. Local consolidative therapy vs. maintenance therapy or observation for patients with oligometastatic non-small-cell lung cancer: long-term results of a multi-institutional, phase II, randomized study. J Clin Oncol 2019; 37: 1558-1565.

107 Petty WJ, Urbanic JJ, Ahmed T, et al. Long-term outcomes of a phase 2 trial of chemotherapy with consolidative radiation therapy for oligometastatic non-small cell lung cancer. Int J Radiat Oncol Biol Phys 2018; 102: 527-535. 